\title{
Cenicienta en Alajuelita
}

\author{
Silvia Méndez Anchía \\ Magister en Psicopedagogía, Universidad de La Salle. Catedrática de la Universidad Estatal a Distancia. \\ E-mail: smendez@uned.ac.cr
}

Recibido: 24 de Octubre 2012 • Aceptado: 19 de Febrero 2013

\section{RESUMEN}

En este ensayo, analizo la lectura de tres versiones del cuento de "La Cenicienta" (la de Perrault, una de los hermanos Grimm y La Cenicienta que no quería comer perdices, de Nunila López y Myriam Cameros) que hace un grupo de mujeres en proceso de recuperación de la adicción a las drogas, durante un taller realizado en San Felipe de Alajuelita (Costa Rica) entre agosto del 2010 y enero del 2011. Sigo, para su presentación, las tres etapas de los esquemas del análisis estructural propuesto por Loup, Slama y Choukroun, así como las nociones de ayudante y oponente de Greimas. Dentro de la situación inicial negativa, las participantes se identifican con la marginalidad de Cenicienta, pero no con sus virtudes; también se identifican con la maldad y el castigo que reciben sus oponentes (las hermanastras) y con el actuar incierto del príncipe. Reconocen, en la etapa de tránsito hacia la meta deseada, la intervención, en sus vidas, de ayudantes, asociados mayormente con la voluntad divina, aunque reconocen su propia voluntad de ruptura con ciertos hábitos como una base para el cambio. Vislumbran, en la situación final positiva, es decir, al completar su proceso de recuperación, la posibilidad de hallar aceptación y comprensión a su dolor por parte de otro, pero principalmente a la luz de una justificación del sufrimiento como camino para llegar a Dios.

Palabras clave: Cenicienta, lectura, drogodependencia, mujeres, Alajuelita.

\section{ABSTRACT}

In this essay, I analyze the reading of three versions of the fairy tale "Cinderella" (The one of Perrault, one of the Grimm brothers and Cinderella would not eat partridges, by Myriam Lopez and Nunila Cameros) of a group of women in process of rehab from addiction to drugs, during a workshop in San Felipe de Alajuelita (Costa Rica) between August 2010 and January 2011. I follow, for their presentation, the three stages of structural analysis schemes proposed by Loup, Slama and Choukroun as well as the notions of helper and opponent proposed by Greimas. Within the initial negative situation, the participants identify themselves with Cinderella's marginality, but not with her virtues. Furthermore, they also identify themselves with the evil and the punishment her opponents (the step-sisters) receive and with the Prince's uncertain act. They recognize, in the transition stage to the desired goal, the mediation, in their lives, of helpers, mostly associated with the divine will, although they know their own will to break with certain habits as a basis for changing. The women glimpse, in the final positive situation, that is to say, when they complete the recovery process, the possibility of finding acceptance and understanding to their pain by another one, but mainly in the light of a justification of suffering as the path to reach God.

Key words: Cinderella, reading, drug addiction, women, Alajuelita. 


\section{Introducción}

La relación entre la lectura de textos literarios y el conocimiento de las emociones propias ha sido señalada por estudiosos de varias disciplinas (Bettelheim, 1988; Larrosa, 1998; Brasey, 2001; Grasso-Fitzpatrick, 2001; Lipkin, 2001; Woloschin y Ungar, 2001; Johnston, Breunig y Garrity, 2002; Brasey y Debailleul, 2003; Bucay, 2003; Ortner, 2003; Doria, 2004; Ortín y Ballester, 2005; Pinkola, 2009). Según Michélle Petit (1999: 37), quienes escriben literatura hacen posible que las personas lectoras conozcan sus propios estados anímicos, e incluso los compartan; "gracias a sus historias, nosotros escribimos la nuestra, entre líneas".

Ese conocimiento propio que se alcanza mediante la lectura de textos literarios puede favorecerse con una mediación psicopedagógica en contextos formales, como una clase de literatura en secundaria, y también en experiencias no formales, como un taller de lectura con personas adultas.

Entre agosto del 2010 y marzo del 2011, estuve colaborando en el "Proyecto intercátedras para la prevención de la adicción a drogas en la comunidad de Alajuelita", promovido por la Escuela de Ciencias Sociales y Humanidades de la Universidad Estatal a Distancia (Costa Rica), específicamente con un taller de lectura de textos literarios dirigido a mujeres adultas en proceso de recuperación que estaban internas en un albergue en San Felipe de Alajuelita. El grupo lo conformaban, en promedio, doce participantes, aunque, de una sesión a otra, el número podía variar por la salida y el ingreso de personas al proceso de recuperación.

Al consultarles sobre sus preferencias de lectura, me solicitaron, entre otros textos, los cuentos de hadas. Algunas de las participantes se refirieron específicamente a "La Cenicienta". Este es un cuento maravilloso ampliamente difundido. Una de sus versiones más antiguas es la denominada "Cenicienta egipcia" (Sanz Díez, 2004: 89). Junto con otros siete cuentos y con el nombre de "Cenicienta o la zapatilla de cristal" aparece en el volumen de 1697, Histoires ou contes du temps passé, de Charles Perrault; también forma parte de la recopilación de 200 relatos que hicieron los hermanos Grimm en la primera mitad del siglo XIX (Gillig, 2000: 32-43). En 1892 este texto contaba con 345 versiones (Cantillano, 2006: 8), de las cuales 38 son francesas y las hay también dentro de la literatura de la India, las Filipinas, África y América (Gillig, 2000: 23). En Costa Rica, está la muy conocida de Carmen Lyra, titulada "La negra y la rubia", que se encuentra recogida en los Cuentos de mi Tía Panchita, de 1920. Los relatos en torno a este personaje siguen produciéndose hoy, con diversidad de variantes; por ejemplo, $\mathrm{La}$ Cenicienta rebelde, de Ann Jungman (2002); "La historia de Cenicienta tal como me la contaron a mí”, de Adela Basch (2009); La Cenicienta que no quería comer perdices, de Nunila López Salamero y Myriam Cameros Sierra (2009); y "De cómo la Cenicienta superó su extraño insomnio", de Evelyn Ugalde (2011).

La principal razón que citaron las participantes para leer este relato es la presencia del hada madrina; sin embargo, otras habían pedido que no fuera "siempre de lo mismo", de lo que ellas ya sabían. Por tal razón, seleccioné como texto inicial uno de los hermanos Grimm (1976), que es menos conocido por el gran público: en este, la madre muerta, transformada en elementos de la naturaleza -un avellano y un pájaro blanco-, ayuda a Cenicienta, y las hermanastras acaban ciegas como castigo a su maldad. Seguimos con una versión con la que podían estar más familiarizadas, la de Charles Perrault (2010), en que interviene el hada madrina, y las hermanastras terminan casadas con dos señores de la corte; esta podría resultarles más conocida, porque se corresponde, en estos elementos, con la cinematográfica de Walt Disney. Y ante el interés que despertó, en el transcurso de las discusiones, la función del hada madrina, añadí un texto marcadamente paródico donde este personaje cumple un papel destacado; se trata de La Cenicienta que no quería comer perdices, cuya consigna (" $¡$ basta!") podría resultar significativa de acuerdo con la situación vital de las participantes. 
La dinámica de trabajo consistió en la lectura de los tres textos literarios (uno por sesión), seguida por preguntas orientadas hacia la identificación de las lectoras con algunos elementos del relato. Brasey y Debailleul (2003: 36) apuntan a la identidad entre el cuento y la persona que lo lee, la cual permite que esta última descubra, como reflejados en el espejo de la ficción, aspectos de su propia vida: "porque existe una identidad profunda entre nosotros y el cuento: el cuento es nuestra historia puesta en escena bajo la forma metafórica de aspectos de nosotros mismos que ignoramos, que rechazamos o que no sabemos ver tal y como son". Esta forma de trabajar con los relatos posibilita que las participantes fortalezcan sus habilidades de conocimiento propio.

Para estructurar el análisis de las intervenciones de las participantes en relación con los distintos relatos de Cenicienta, tomé como base la aplicación pedagógica de los esquemas del análisis estructural de Loup, Slama y Choukroun (Gillig, 2000: 68-70), quienes organizan los cuentos maravillosos en tres momentos: situación inicial negativa, tránsito y situación final positiva. También, las categorías actanciales de ayudante y oponente según Greimas; de acuerdo con estas, el héroe, en su intento por superar las pruebas que le permitirán alcanzar el objeto deseado, recibe la colaboración de un protector o amigo, quien interviene para ayudarle a vencer al antagonista y alcanzar, de esta forma, su propósito (Marchese y Forradellas, 2000: 14).

La caracterización de cada una de esas etapas desde la óptica de las participantes, se basa en la transcripción de sus intervenciones durante la dinámica posterior a la lectura de los textos. Los ejemplos tomados del discurso de estas mujeres para ilustrar el análisis aparecerán referidos como "diario de campo" (DC), con la fecha de la sesión a que correspondió. Por tratarse de una transcripción del discurso oral, todas las expresiones que figuran en cursiva responden a una intención mía de destacarlas.

\section{Desarrollo}

Con base en la aplicación pedagógica de los esquemas de análisis estructural, el cuento de " $\mathrm{La}$
Cenicienta" corresponde al modelo de búsqueda, que parte de una situación inicial negativa (ausencia, víctima) y concluye con una situación final positiva (glorificación del héroe), cuyo logro depende de una etapa de tránsito en la cual el héroe debe superar ciertas pruebas (Loup, Slama y Choukroun, citados por Gillig, 2000: 68-70).

\section{Cenicientas malvadas (situación inicial negativa)}

"Todas tenemos nuestra historia de Cenicienta. Todas hemos pasado por algo que nos llevó a estar aqui". (DC, 27-11-10)

En la etapa inicial, la heroína se halla en una circunstancia problemática: es víctima del desprecio y abuso por parte de su madrastra y hermanastras, quienes fungen como oponentes. El habla común ha extendido el término "cenicienta" a la "persona o cosa injustamente postergada, despreciada" (RAE, 2001), siendo entonces sinónimo de relegación, de humillación.

Esa experiencia inicial traumática recibe muchos comentarios de las participantes. Una de ellas manifiesta su identificación con Cenicienta y la satisfacción que eso le produjo: "Me gustó, porque es una muchacha a quien la humillaba la sociedad. A nosotros cuando andamos en drogas muchas veces nos humillan, nos desprecian, nos hacen a un lado..." (DC, 27-11-10). Otras se refieren al daño emocional que les causó esta situación: "Todas tenemos una herida en nuestro corazón, no hay ninguna de nosotras que no haya sentido miedo alguna vez" (DC, 11-12-10); "la humillación es otra herida en el corazón" (DC, 11-12-10). Como consecuencia, la estima propia se debilita: "A veces cuando estamos en una familia y llega otra persona nos desplaza, nos hace a un lado; las preferencias por otro hermano nos bajan la autoestima, pero uno tiene que valorarse a uno mismo" (DC, 27-11-10).

Las participantes se identifican con la humillación y relegación de Cenicienta. Esta experiencia les resulta común por la condición de marginalidad a que las expone -en su familia y en 
la sociedad en general- la adicción a las drogas. A ello se suma la subordinación que implica el ser mujeres y, además, habitar en una de las comunidades de Costa Rica más deprimidas económica y socialmente como lo es el cantón de Alajuelita (Ross, 2011; Solano, 2011).

Destacan las cualidades morales de la heroína, pero no se identifican con estas, sino más bien desean emularla, debido a que ellas no las poseen: "Yo quiero un hada de esas. Se llama Jesús. Ella era buena, solo le cambió lo de afuera; a mí tiene que transformarme por dentro: el corazón, ser honesta, que no me vuelvan a humillar más" (DC, 11-12-10). Al respecto, el objeto de su deseo parece no ser tanto el príncipe, como alcanzar el estado de gracia en que se halla Cenicienta: "Poder tener el corazón que tenía ella. Tanto que la humillaron, tanto que le hacían ella no guardaba rencor. Lo importante era el corazón de ella, que pudo perdonar" (DC, 11-12-10). Aquí se establece una diferencia fundamental entre la protagonista, quien encarna virtudes cristianas (humildad, honestidad, perdón, espíritu de servicio), y sus oponentes, quienes representan la soberbia y la maldad: "Dormir entre cenizas, la ayuda de los auxiliares mágicos y el comportamiento dulce y bondadoso de Cenicienta, se contraponen a la excesiva elegancia, tiranía y maldad de su madrastra y hermanastras" (Sanz, 2004: 90).

Ahora bien, en concordancia con la falta de virtudes que reconocen en ellas mismas, las participantes se identifican con las oponentes de Cenicienta, justamente por sus defectos.

Primero, se refieren a rasgos como la superficialidad y el orgullo de estas: "Las hermanastras muy materialistas; se dejaban llevar por lo material" (DC, 11-12-10), aspecto en que estos personajes se oponen radicalmente a la protagonista.

En un segundo momento, aluden a la maldad de estas mujeres, enfatizando en su capacidad para dañar a otros: "Las hermanastras nunca pensaron en los sentimientos de ella: el veneno que tenían por dentro se lo tiraban a ella; no pensaban en las consecuencias (quedaron ciegas); cómo ellas no se pusieron en los zapatos de Cenicienta" (DC, 27-11-10). En esta expresión dejan ver también un elemento fundamental, relacionado con las consecuencias, en particular con el castigo a la maldad, que se desprende de la versión de los hermanos Grimm ${ }^{1}$.

Y aquí es justamente donde opera la identificación. Para las participantes, la maldad de las hermanastras y el castigo que recibieron son aspectos que también se aplican a la vida de ellas: "Cada una de nosotras fuimos ogros al hacer sufrir a otros, como las hermanastras. Ese daño se devuelve como las palomas, que las dejaron sin ojos. Estábamos ciegas por la droga" (DC, 27-1110), a lo cual añaden: "La maldad atrae maldad. Lo que uno siembra recoge" (DC, 27-11-10).

En estas transcripciones del discurso de las participantes, aparece un elemento básico: esa sustancia, "el veneno que tenían por dentro", el cual las dejó "sin ojos" y, de manera más explícita, se definen a ellas mismas como "ciegas por la droga". Esas hermanastras malvadas, incapaces de pensar en el sufrimiento ajeno, son ellas mismas en su contacto con las drogas.

Finalmente, rescatan el factor arrepentimiento, tomado de la versión de Perrault: "Las muchachas se arrepintieron de lo que le habían hecho a ella" (DC, 11-12-10).

1. "Cuando llegó el día de la boda, se presentaron las falsas hermanas, deseosas de congraciarse con Cenicienta para participar de su suerte. Cuando los novios se encaminaron a la iglesia la mayor de las hermanas iba a su derecha, y la menor a su izquierda: entonces las palomas, de sendos picotazos, les sacaron un ojo a cada una. Después, cuando salieron, la mayor iba a la izquierda y la menor a la derecha: entonces las palomas, de sendos picotazos, les sacaron un ojo a cada una. Y de este modo, como castigo por su maldad y falsedad, quedaron ciegas para el resto de sus vidas". (Grimm y Grimm, 1976: 192)

2. "Entonces las dos hermanas la reconocieron como la persona que habían visto en el baile. Se arrojaron a sus pies para pedirle perdón por todos los malos tratos que le habían infligido. Cenicienta las hizo levantarse y les dijo, abrazándolas, que las perdonaba de todo corazón y les rogó que siempre la quisieran.

Fue conducida ante el joven príncipe, vestida como estaba. Él la encontró más bella que nunca, y pocos días después se casaron. Cenicienta, que era tan buena como hermosa, hizo llevar a sus hermanas a morar en el palacio y las casó en seguida con dos grandes señores de la corte". (Perrault, 2010) 
Según autores de influencia psicoanalítica, como Bettelheim (1988: 39) y Pinkola (2009: 115124), tanto los personajes bondadosos como sus oponentes representan, en los cuentos maravillosos, diversos aspectos de la psique. En el caso que nos ocupa, las participantes experimentan una supremacía de su "mundo oscuro" -ese contacto con lo real que, según Propp (citado por Sanz, 2004: 90), es representado por la figura del agresor en los cuentos maravillosos- sobre el "mundo de la claridad", que parecen no hallar en su vida interior.

En síntesis, a la caracterización que las participantes hacen de ellas mismas, integran elementos tanto de la heroína como de sus oponentes. Sin embargo, en ambos casos se trata de aspectos negativos: la humillación de la primera y la maldad de las últimas. Estas mujeres ven en otros lo positivo (las virtudes están en Cenicienta, no en ellas) y se atribuyen a sí mismas los rasgos negativos (la capacidad de dañar a otros y dañarse, que han visto reflejadas en las acciones de las hermanastras). Esto determina que exista en ellas una doble intención: de acercamiento a la heroína, por sus virtudes cristianas, y de evitación de las hermanastras, por sus defectos y su maldad.

Tal dinámica interna las lleva a negar por completo la influencia del medio conflictivo en que se desenvuelven y a asumir la responsabilidad absoluta por el proceso de degradación que han sufrido. En su discurso, la problemática de adicción que las afecta se reduce a una cuestión axiológica, dejando de lado aquellos factores de riesgo para el consumo de drogas (pobreza, violencia intrafamiliar, deserción escolar, falta de oportunidades laborales; Solís, Sánchez y Cortés, s.f.: 20-26) que caracterizan la comunidad donde habitan.

Esta forma de mirar su propia condición -ya sea que provenga de un ejercicio introspectivo como de otras instancias sociales con que están en contacto- resulta, sin duda, un factor alienante. En un análisis del cuento de "Vasalisa, la Sabia", Clarissa Pinkola (2009: 122) se refiere a esta difícil condición:

\begin{abstract}
"Nosotras también estamos pinzadas cuando la familia putativa que llevamos dentro o que nos rodea nos dice que no servimos para nada e insiste en que nos centremos en nuestros defectos en lugar de fijarnos en la crueldad que se arremolina a nuestro alrededor, tanto si esta emana de nuestra psique como si emana de la cultura a la que pertenecemos".
\end{abstract}

Este es el panorama que se desprende de las intervenciones de las participantes, a la luz de la primera etapa del modelo de búsqueda de los cuentos maravillosos. Así interpretan la situación inicial negativa, de humillación, que comparten con la protagonista.

El siguiente apartado se centra en la etapa del tránsito de ese estado de degradación hacia la meta anhelada.

\section{Auxilio externo y fuerza interior: etapa de tránsito}

"Fuimos a buscar la felicidad a un lugar donde no existia”. (DC, 8-1-11)

El héroe de los cuentos maravillosos lleva a cabo la búsqueda del objeto deseado, para lo cual ha de superar ciertas pruebas (Gillig, 2000: 6970). Cenicienta recibe la ayuda de elementos mágicos (su madre muerta, un avellano, un pájaro blanco, su hada madrina), para finalmente salir vencedora en la prueba de identidad (del zapato) y casarse con el príncipe.

En la lectura que hacen las participantes de ellas mismas a la luz de este cuento, los ayudantes adoptan diversas formas, pero todos intervienen en la vida de estas mujeres para indicarles algo en relación con la gran prueba a que están siendo sometidas: su proceso de recuperación de la adicción a las drogas. Este proceso implica tanto una acción externa como una procedente del interior; en la primera, el papel de las participantes está marcado por la pasividad, mientras que en la acción interna hay un movimiento hacia su propia capacidad de cambio.

Al reflexionar acerca del significado de los ayudantes en la versión de los hermanos Grimm, los asocian con el fin del sufrimiento y con la 
intervención divina: "Las palomas y el árbol que ayudan a la Cenicienta significan que Dios sabe por qué hace las cosas; todo esto era un instrumento para que la Cenicienta no sufriera tanto" (DC, 27-11-10). También los relacionan, siguiendo con una lectura mágico-religiosa, con ángeles que aparecen para impulsarlas a empezar de nuevo:

“Me gusta porque la mamá y las palomas la ayudaron. A veces una persona que no está viva, como la mamá de la Cenicienta, puede ayudarnos: como mi papá, que me dijo que me alejara de los vicios y que consiguiera un buen hombre. Un montón de personas le ayudan a uno, son como ángeles, en mi experiencia ya nadie creía en uno; de un momento a otro aparece una persona que quiere ayudarlo y le muestra a uno cómo es empezar de nuevo; a uno le cuesta mucho creer que las personas son incondicionales, claro no son tan incondicionales: esperan a cambio mi recuperación”. (DC, 27-11-10)

O simplemente con personas bondadosas que les ayudan en su proceso de recuperación: "Muchas veces hay gente que nos ayuda a renunciar a algo que nos hace daño" (DC, 27-11-12).

En la versión de Perrault, aparece el hada buena, una especie de ángel guardián que presta auxilio al héroe para alcanzar lo deseado, acentuándole las virtudes (Gillig, 2000). Ello es justamente lo que las participantes leen en el cuento: la exteriorización que hace el hada de la belleza interior de la protagonista: "La hada (sic) la trabajó un poquito, pero Cenicienta era una mujer como deberíamos ser todos: honestos, honrados, responsables, sinceros, tener buen compañerismo, sin enredarse con los del mundo" (DC, 11-12-10); "Por buen corazón y humildad, Dios le mandó un hada madrina para rescatarla" (DC, 11-12-10).

Y aquí aparece su deseo de ser como Cenicienta, lo cual esperan alcanzar por la intervención divina. A esta hada, no le piden la acentuación de las virtudes -que no reconocen como parte de ellas mismas-, sino un cambio total en su vida interior: "Yo quiero un hada de esas. Se llama Jesús. Ella era buena, solo le cambió lo de afuera; a mí tiene que transformarme por dentro: el corazón, ser honesta, que no me vuelvan a humillar más" (DC, 11-12-10).

Con la lectura de La Cenicienta que no quería comer perdices, sus comentarios se dirigen hacia el reconocimiento de una capacidad interna para ser agentes de su proceso de transformación. Este relato paródico presenta la vida de Cenicienta cuando ya se ha casado con el príncipe; los esfuerzos que ella hace con tal de complacerlo, la alejan de su propio deseo, hasta que aparece el hada Basta, quien la invita a romper definitivamente con todo aquello que responde a las demandas de los otros.

Esta historia motiva a las participantes para que reconozcan, en sus propias vidas, la necesaria renuncia a ciertos hábitos dañinos y el instante de ruptura en que esta se da: "El hada madrina como la pintan (Basta) significa renunciar a cosas a las que uno está acostumbrado. Dice Rocío Durcal que la costumbre es más fuerte que el amor. Uno se habitúa a muchas cosas" (DC, 8-1-11); "El extracto de lo que hemos hablado es la palabra costumbres, que va ligado a hábito y a rutina. Caemos en un círculo vicioso. Nosotras mismas nos hicimos una introspección" (DC, 8-111); "Ese basta que es 'puede ser este instante'. Cuando estaba yo en Lomas y dije 'basta', voy jalando. Me causó bonito por la regordeta, el hada madrina, no trata de revestirla, sino una persona acorde a ella" (DC, 8-1-11).

En la vida de muchas mujeres -no necesariamente con adicción a drogas- existe esa necesidad de ruptura radical con determinadas situaciones que, formando parte de su vida cotidiana y siendo por tanto naturalizadas por la sociedad patriarcal, llegan a un nivel en que las hacen experimentar saturación (Coria, 2010: 27).

En esta etapa de tránsito hacia el objeto deseado, que en el caso de las participantes, como lo señalé antes, parece ser más un estado de gracia que el amor del príncipe, un rasgo del cuento que comentaron fue la perseverancia: "El zapato es lo bueno que el príncipe buscaba en esa persona (paso a paso a la vez sin mirar atrás)" (DC, 27-11-10). 
Para estas mujeres, Cenicienta insistió en las pruebas que se le impusieron, hasta llegar a la última, la de identidad, que le garantizaría el final feliz. Sin embargo, ellas no se identifican con la protagonista en este aspecto:

"El zapato es una pista de cómo llegar al camino de la felicidad; a veces uno no ve las oportunidades que tiene; a pesar de todo lo que le pasaba [Cenicienta] perseveró en la vida; tuvo trascendencia (pasó los obstáculos y siguió adelante”. (DC, 27-11-10)

También el príncipe se mantiene firme en alcanzar su meta. En la siguiente expresión se lo asocia, por esta característica, con Dios: "Lo que Dios hace con uno: como el príncipe que insistió e insistió hasta llegar a ella"; sin embargo, continúa así: "Dios siempre nos da la cara, pero uno no lo ve. También nosotras somos como el príncipe que a veces ve bien y a veces no ve bien (en vez de llevarse a Cenicienta, se lleva a las hermanastras)" (DC, 27-11-10). Nuevamente está el tema de la ceguera, que en otras expresiones las participantes han asociado con la influencia de las drogas en sus vidas, y aquí sí hay una identificación con el hijo del rey, pero cuando este falla: si es bueno, ve bien, es perseverante y se muestra con claridad, el príncipe es Dios; mas cuando falla en su empresa, dicho personaje puede ser una de estas mujeres, que han perdido la vista y, con ella, el "camino de la felicidad".

Se trata del mismo movimiento afectivo descrito en el apartado precedente, de reconocer en otros (Cenicienta, ayudantes, Dios, príncipe) las virtudes de que ellas carecen y asumir una serie de defectos, a los que agregan ahora uno relacionado específicamente con el proceso de la recuperación, la inconstancia.

Un punto de ruptura lo marcan los comentarios a propósito de La Cenicienta que no quería comer perdices, mediante los cuales las participantes rescatan su propia capacidad volitiva y transformadora de su realidad, previa aceptación de que existe una circunstancia que las tiene sumidas en la negación de ellas mismas.

\section{Dolor y redención: situación final positiva}

En el cuento de "La Cenicienta", el Príncipe Azul simboliza la meta por alcanzar. Esta figura juega un papel determinante en la configuración de las expectativas femeninas, cuya representación social se asienta, según Burin (2006: 80) en roles familiares. El patrón de socialización a que se ven expuestas las mujeres las conduce a definir sus metas con base en la idea del matrimonio, por sobre la realización en cualquier otro ámbito; en este patrón subyace una necesidad psicológica de ser salvadas, de encontrar a alguien que cuide de ellas (Dowling, 2006: 41).

En la lectura que las participantes hacen del príncipe como expectativa de vida, se deja ver el desamparo en que las ha sumido el rechazo y la soledad; en síntesis, la marginalidad en que viven. Este personaje viene entonces a representar la aceptación, compañía y protección anheladas por ellas:

"Todas soñamos con un Príncipe Azul. Una persona que nos ame como somos, que nos motive, que nos dé apoyo, que comparta; no es plata para viajar, sino la media naranja, la parte linda; uno necesita a una persona para estar con uno. Un Príncipe Azul es alguien que lo cobija a uno". (DC, 27-11-10)

Sin embargo, hay una fractura en su discurso, que manifiesta el influjo del medio familiar de origen en su proceso de adicción a las drogas, en particular de un lazo paterno que, lejos de servir de sostén o eje estructurador en la vida de estas mujeres, las socializa en el mundo de la drogodependencia: "El primer Príncipe Azul que uno tiene en la vida es el papá: yo fui los ojos de la cara de él, la más parecida, con él aprendí a tomar [dos participantes más dicen que ellas también]" (DC, 27-11-10).

La recuperación, para estas mujeres, constituye un viaje tras el cual confían en hallar a un otro que comprenda y acepte sus historias llenas de ese dolor que representa la exclusión, de la cual ellas conciben que difícilmente pueden salir por un esfuerzo propio -se consideran la "parte fea" de la media naranja- ni por la salvación de 
un compañero -príncipe-padre que les ha enseñado a beber-, sino solo por la intervención de un poder superior. Nuevamente figura, en su discurso, el tema de la redención por parte del príncipe, pero esta vez dicho personaje actúa como metáfora de un Dios al que se accede por la vía del sufrimiento: "Cenicienta se salva casándose con el príncipe, por las zapatillas (el cambio en ella, ya no la van a humillar por nada)" (DC, 1112-10), "el zapato son los golpes de la vida, son una señal para que el príncipe Dios lo encuentre a uno" (DC, 27-11-10).

Para ese dolor generado por la marginación, buscan alivio en un ser superior que sale a su encuentro y les dona lo que podría considerarse una felicidad verdadera, basada en aceptación, comprensión, apoyo. En otras palabras, su meta sería pasar de esa felicidad falsa y efímera que proporcionan las drogas a comprender el dolor de la existencia humana mediante la idea de un dios que justifica su sufrimiento (Martinelli y Morales, 1998: 121).

Si bien es cierto la situación por la que atraviesan estas mujeres responde a sus experiencias personales, también es necesario considerar el contexto social en que se desenvuelven. Se trata del marco más amplio de una cultura donde las relaciones interpersonales se han visto empobrecidas hasta el punto de que se puede hablar de "un creciente analfabetismo afectivo" (Restrepo, 2001: 199), a la vez que predomina el malestar por la presencia de relaciones injustas, lo cual se torna más evidente en el caso de ellas, al habitar en una comunidad tan vulnerable como lo es el cantón de Alajuelita. Esta circunstancia se halla muy bien descrita en las palabras de Martinelli y Morales (1998):

Las drogas convocan a quienes ante el silencio de la risa cósmica o el ruido de la ciudad ingrata acuden a la necesidad de creer que sí hay algo que los salve, que los eleve, que los cure. ¿Qué los cure de qué? Del desempleo, del maltrato, de la sumisión ante el estado o la empresa, la familia o la globalización económica (p. 122).

\section{Conclusiones}

"Con palabras se nos expulsa, con otras palabras se nos da acogida". (Petit, 1999: 82)

¿Cómo un texto que presenta una situación cruel y común a las lectoras puede producir en ellas una sensación de bienestar? Justamente porque les provee de palabras mediante las cuales comprender su situación vital, sin importar si esta ha sido agradable o no (Petit, 1999: 35).

En el ejercicio de lectura que he analizado, estas mujeres de Alajuelita han podido darle voz a un sufrimiento que tiene como base su adicción a las drogas y que ha dejado ver la humillación y marginalidad en que viven, igual que la Cenicienta. Pero en su caso, por su condición de adictas y las circunstancias socioculturales en que se desenvuelven, sufren todavía más, ya que se perciben viciosas como las hermanastras malvadas, ciegas, merecedoras de castigo y, por su actuar incierto, como el príncipe, cuando este se equivoca y pierde el rumbo para llegar a su meta.

En su camino hacia el encuentro con las virtudes de que carecen, reconocen la ayuda de personas (algunas veces instrumentos divinos) que podrían infundirles ánimo y guiarlas en su proceso de recuperación. También aceptan que el cambio procede de una opción interior que las condujo a romper con unos hábitos a los cuales recurrieron en busca de una felicidad ilusoria.

Al final de su proceso de recuperación, esperan encontrar aquello de que tanto carecen: aceptación, comprensión, compañía, lo cual puede provenir de una persona, pero lo vislumbran más en la figura de un Dios capaz de valorar su sufrimiento.

En síntesis, estas mujeres se reconocen llenas de defectos; de ahí la identificación con las hermanastras y con un príncipe que, aunque simboliza la meta por alcanzar, también se equivoca. Por eso anhelan las virtudes de Cenicienta, las cuales no llegan a encontrar dentro de ellas mismas. Es como si se apropiaran de lo malo del medio en que se desenvuelven y vaciaran de sí todo 
lo bueno, depositándolo en otros (Cenicienta, Dios, el príncipe, los ayudantes).

Ante la dificultad de vivir en un mundo sin utopías, que ha perdido muchos de sus referentes de sentido existencial (religiones, opciones políticas, relaciones de pareja), ellas incorporan el vacío social, lo hacen suyo. Son mujeres que no leen bien las pistas de la vida, que no encuentran sentido a la existencia en una sociedad vulnerable como la que representa el cantón de Alajuelita, y la única clave que poseen para comprender el dolor en sus vidas consiste en explicarlo a la luz de características de su personalidad y comportamientos que valoran como defectuosos.

Aunque el marco social se revela explicativo de las condiciones por las que atraviesan las participantes, la lectura que ellas hacen de "La Cenicienta" se inscribe, más bien, en la tradición del tempos fugit medieval, que describe el mundo, tal y como lo plantea Álvarez (2011: 71), “como lugar de corrupción y cenizas, lugar de mero trámite para la penitencia". En ello se destaca la influencia de un discurso religioso como forma de comprensión del sufrimiento humano.

\section{Referencias}

Álvarez, Blanca (2011). La verdadera historia de los cuentos populares. Madrid: Ediciones Morata.

Basch, Adela (2009). La historia de Cenicienta tal como me la contaron a mí. En Adela Basch, Angelo Machado, Beatriz García Huidobro, Carolina Alonso, Julio Calvo Drago, Miguel Ángel Tenorio, David Hernández Labastida, Heriberto Tejo y Myriam Yagnam. De verdad, fue así... cuentos clásicos recontados (pp. 6-19). Sao Paulo: Coedición Latinoamericana.

Bettelheim, Bruno (1988). Psicoanálisis de los cuentos de hadas (S. Furió, trad.). Barcelona: Crítica.

Brasey, Edouard (2001). Encuentre su verdad en los cuentos de sabiduría. Una vía psicológica e iniciática de autoconocimiento (M. Lamberti, trad.). Madrid: EDAF.

Brasey, Edouard; Debailleul, Jean-Pascal (2003). Vivir la magia de los cuentos. Cómo lo maravilloso puede transformar nuestras vidas (M. Vásquez, trad.; $4^{\mathrm{a}}$. ed.). Madrid: EDAF.

Bucay, Jorge (2003). Cuentos para pensar. México: Océano.
Burin, Mabel (2006). Ámbito familiar y construcción del género. En Mabel Burin e Irene Meler. Género y familia. Poder, amor y sexualidad en la construcción de la subjetividad (pp. 71-86). Buenos Aires: Paidós.

Cantillano, Odilie (2006). El pozo encantado. Los cuentos de mi tía Panchita de Carmen Lyra. San José: EUNED.

Coria, Clara (2010). Decir basta. Una asignatura pendiente. Buenos Aires: Paidós.

Doria, José María (2011). Cuentos para aprender a aprender. Madrid: Gaia Ediciones.

Dowling, Colette (2006). El Complejo de Cenicienta. El miedo de las mujeres a la independencia (tr. A Pigrau). México: De Bolsillo.

Gillig, Jean-Marie (2000). El cuento en pedagogía y reeducación (R. L. González, trad.). México: FCE.

Grasso-Fitzpatrick, Jean (2001). Cuentos para leer en familia. Historias que favorecen el desarrollo sano de los niños. Barcelona: Paidós.

Grimm, Jacob; Grimm, Wilhelm (1976). Cuentos (P. Gálvez, trad.). Madrid: Alianza.

Johnston, Janet R.; Breunig, Karen; Garrity, Carla; Baris, Mitchell (2002). Cuentos para enseñar a tus hijos a entender el divorcio (J. C. Guix, trad.). Barcelona: Paidós.

Jungman, Ann (2002). La Cenicienta rebelde (12a . ed.). Barcelona: SM.

Larrosa, Jorge (1998). La experiencia de la lectura. Estudios sobre literatura y formación ( $2^{\mathrm{a}}$. ed.). Barcelona: Laertes.

Lipkin, Lisa (2001). Aprender a educar con cuentos (J. C. Guix, trad.). Barcelona: Paidós.

López Salamero, Nunila; Cameros Sierra, Myriam (2009). La Cenicienta que no quería comer perdices. Barcelona: Planeta.

Marchese, Angelo y Forradellas, Joaquín (2000). Diccionario de retórica, crítica y terminología literaria (J. Forradelas, trad.; $7^{\text {a }}$ ed.). Barcelona: Ariel.

Martinelli Herrera, Marcela; Morales Ascencio, Helí (1998). Caleidoscopio de la ebriedad. Freud, la cocaína y el nacimiento del psicoanálisis. Helí Morales y Daniel Gerber (compiladores). Las suplencias del nombre del Padre (pp. 95-125). México: Siglo XXI.

Ortín, Bernardo; Ballester, Trinidad (2005). Cuentos que curan. Conocernos mejor con el poder terapéutico de los cuentos. Barcelona: Océano. 
Ortner, Gerlinde (2003). Cuentos que ayudan a los niños (M. Barea, trad.; $9^{a}$. ed.). Málaga: Sirio.

Petit, Michèle (1999). Nuevos acercamientos a los jóvenes y la lectura (R. Segovia y D. L. Sánchez, trads.). México: Fondo de Cultura Económica.

Perrault, Charles (2010). La Cenicienta. Recuperado de http://www.ciudadseva.com/textos/cuentos/fran/perrault/cenicien.htm

Pinkola Estés, Clarisa (2009). Mujeres que corren con los lobos (M. A. Menini, trad.). Barcelona: Zeta Bolsillo.

Real Academia Española (2001). Diccionario de la lengua española (22 $2^{\mathrm{a}}$. edición). Madrid: Espasa.

Restrepo, Luis Carlos (2001). La fruta prohibida. La droga como espejo de la cultura. Bogotá: Panamericana.

Ross, Amy (2011, 26 de octubre). Pobreza pone a Alajuelita en el último lugar de desarrollo. La Nación (Costa Rica). Recuperado de: http://www.nacion.com/2011-10-26/
ElPais/Pobreza-pone-a-Alajuelita-en-el-ultimo-lugarde-desarrollo.aspx

Sanz Díez, María (2004). Cenicienta. Trama y Fondo (17), 87-94.

Solano, Hugo (2011, 27 de octubre). Alajuelita cayó al último lugar en índice de desarrollo humano. Al Día (Costa Rica). Recuperado de: http://www.aldia.cr/ad_ee/2011/ octubre/27/noticias-del-dia2956631.html

Solís Rojas, Luis R.; Sánchez Guerrero, Alejandro; Cortés Fuentes, Rafael (s.f.). Drogas. Preguntas más frecuentes. San José: ICD, IAFA, MEP, ONUDD, Centros de Integración Juvenil.

Ugalde, Evelyn (2011). De cómo la Cenicienta superó su extraño insomnio. En Evelyn Ugalde. Cuando los cuentos crecen (pp. 35-37). Santo Domingo: Santuario.

Woloschin, Liliana; Ungar, Antonio (2001). Contar cuentos. Barcelona: RBA Libros. 